\title{
Functional mitral regurgitation
}

\author{
Om Prakash Yadava ${ }^{1}$ (D) Jose Luis Pomar ${ }^{2,3}$
}

Received: 23 January 2019 / Accepted: 5 February 2019/Published online: 9 March 2019

(C) Indian Association of Cardiovascular-Thoracic Surgeons 2019

\begin{abstract}
Dr. O.P. Yadava, Editor-in-Chief, IJTC, and Dr. J.L. Pomar, Former President, EACTS, discuss issues related to secondary mitral regurgitation (MR). Though it is considered a ventricular disease, mitral valve leaflets are not entirely normal. Alignment of subvalvular apparatus plays a more dominant role than annular dilatation. Early repair is preferred.
\end{abstract}

Keywords Secondary mitral regurgitation $\cdot$ Repair versus replacement $\cdot$ Timing of surgery

The common perception that mitral valve is normal in functional MR is a flawed one $[1,2]$. Dr. Pomar agrees and opines that the substrate of the valve leaflets, including the matrix metallo-proteinases, undergo changes. Multiple factors play a role in the causation of MR. Probably, annular dilatation is not the most important factor, and the alignment of the subvalvular apparatus may have a more dominant role [3]. Prof. Robert Levine from USA has done a lot of work on this front [4]. With primary percutaneous coronary interventions (PCI) becoming universally available, at least in Europe, the secondary MR rates have come down.

Prof. Pomar feels that these patients should be handled early in the course of the disease for better long-term outcomes and these interventions should ideally be performed in specific centres with good results. Dr. Pomar stresses on the fact that it is not the technique of the repair/replacement, but the timing of the surgery, which is most important in these

Electronic supplementary material The online version of this article (https://doi.org/10.1007/s12055-019-00806-1) contains supplementary material, which is available to authorized users.

Om Prakash Yadava

op_yadava@yahoo.com

1 National Heart Institute, New Delhi, India

2 University of Barcelona, Barcelona, Spain

3 EACTS, Windsor, UK patients. This is one field that the interventional cardiologists are going to take over from the surgeons and have in fact already done to a large extent.

Dr. Pomar believes that all annuloplasty rings performed equally well and probably planar rings do just as well as the specialized saddle-shaped rings for annuloplasty of the mitral valve. However, he issues a caveat- with the amount of heterogeneity with heart failure, a one-stop solution does not exist and one must customize options to the patient's needs.

Publisher's note Springer Nature remains neutral with regard to jurisdictional claims in published maps and institutional affiliations.

\section{References}

1. Beaudoin J, Handschumacher MD, Zeng X, et al. Mitral valve enlargement in chronic aortic regurgitation as a compensatory mechanism to prevent functional mitral regurgitation in the dilated left ventricle. J Am Coll Cardiol. 2013;61:1809-16.

2. Grayburn PA. New concepts in functional mitral regurgitation - it is not just a disease of the left ventricle. J Am Coll Cardiol. 2013;61: 1817-9.

3. Nappi F, Avatar Singh SS, Santana O, Mihos CG. Functional mitral regurgitation: an overview for surgical management framework. J Thorac Dis. 2018;10:4540-55.

4. Dal-Bianco JP, Beaudoin J, Handschumacher MD, Levine RA. Basic mechanisms of mitral regurgitation. Can J Cardiol. 2014;30:971-81. 